\title{
Formulation and Evaluation of Floating Polymeric Nanoparticles of Linagliptin in Capsules
}

\author{
D. Prasanthi*, J. Krishna Kumari, S. Hymavathi \\ Department of Pharmaceutics, G. Pulla Reddy College of Pharmacy, Mehdipatnam, Hyderabad, Telangana, INDIA.
}

\begin{abstract}
Objectives: Linagliptin is a BCS class III drug used in treatment of diabetes. In the present study floating polymeric nanoparticles of linagliptin are formulated to increase the residence time of drug in stomach by controlling drug delivery over a prolonged period of time and to increase permeability by nanosized particles, there by bioavailability can be increased. Methods: Polymeric nanoparticles were prepared by desolvation and ion gelation method. The prepared polymeric nanoparticles were evaluated for entrapment efficiency, drug content, percentage yield, diffusion studies and dissolution studies. Results: Among various formulations, GF2 formulation by ion gelation method, CF5 by desolvation (continuous addition) method and IF1 by desolation (intermittent addition) method have shown \% drug release of $91.8 \pm 0.50 \%, 92.8 \pm 0.33 \%$ and $91.5 \pm 31 \%$ in 210 min respectively. GF2 was considered as the optimized formulation based on its high entrapment efficiency of $88.6 \pm 1.09 \%$, cumulative amount permeated of $997.0 \pm 2.15 \mu \mathrm{g} / \mathrm{cm}^{2}$ for $4 \mathrm{hrs}$, Zeta potential $(-20.3 \mathrm{mV})$, particle size $(396 \mathrm{~nm})$ and SEM (spherical and smooth surface). The GF2 formulation was converted into floating drug delivery system with sodium bicarbonate and different concentration of
\end{abstract}

ethyl cellulose, HPMC E15M. GF2 (1:2 ratio of drug:ethyl cellulose) was optimized as it showed prolonged drug release by retaining drug through mucosa of goat with \% drug release $(53.1 \pm 0.50 \%$ at $5.5 \mathrm{hrs})$ in comparison with pure drug $(99.8 \pm 0.19 \%$ at $1 \mathrm{hr})$ and it was stable as per $\mathrm{ICH}$ guidelines. Conclusion: Hence the drug release has been retarded, permeation has been enhanced and residence time of drug in the stomach has been extended by floating polymeric nanoparticles.

Key words: Floating Drug Delivery, Nanoparticles, Polymeric Nanoparticles, Desolvation Method, Ion Gelation Method, Linagliptin.

Correspondence

Dr. D. Prasanthi,

Associate Professor, G. Pulla Reddy College of Pharmacy, Mehdipatnam, Hyderabad-500028, Telangana, INDIA.

Phone: +919490052147

Email: prasanthidhanu@gmail.com

DOI: 10.5530/jyp.2020.12s.43

\section{INTRODUCTION}

Nanoparticles are defined as particulate dispersions or solid particles having size within the range of $10-1000 \mathrm{~nm}$. The drug is dissolved, attached, encapsulated or entrapped, into the nanoparticle's matrix. ${ }^{1}$ Polymeric nanoparticles (PNPs) are prepared from a synthetic or semi synthetic polymeric block to increase the circulation half-life and to reduce phagocytic uptake and inactivation of the therapeutic moiety and can be used to deliver and target therapeutic agents. ${ }^{2}$ They are formulated by incorporating biodegradable polymers in order to maximize tissue compatibility and minimize cytotoxicity. It has been reported that higher entrapment efficiency in PNPs can be achieved by incorporation of drug during their preparation rather than adsorption on preformed nanoparticles. ${ }^{2,3}$ Drug release takes place in polymeric nanoparticles through their simultaneous biodegradation, followed by desorption, diffusion, or erosion. The major goals in designing nanoparticles as a delivery system are to control particle size, surface properties and release of pharmacologically active agents in order to achieve the site-specific action of the drug at the therapeutically optimal rate and dose regimen. ${ }^{1-3}$ Chitosan is a natural polymer obtained by deactivation of chitin. It is biologically safe, non-toxic, biocompatible and biodegradable polysaccharide. Chitosan nanoparticles are formed based on electrostatic interaction between amine group of chitosan and negatively charge group of polyanion such as tripolyphosphate by ion gelation method. ${ }^{4}$ In Desolvation method the protein or polysaccharide in aqueous phase are often desolvated by $\mathrm{pH}$ change or change in temperature by adding appropriate amount of counter ions. ${ }^{4,5}$ It contains three steps: protein dissolution, protein aggregation and protein deaggregation. With the acceptable levels of desolvation and resolvation, the aggregate size might be maintained and eventually the mixtures of nanoparticles are cross linked using glutaraldehyde. The process of removing/replacing solvating water molecules, by a non-solvent, from the hydration shell of a macromolecule is named desolvation., ${ }^{4,6}$

Linagliptin is a BCS class III (high solubility and low permeability) drug used in treatment of diabetes. Though it has high solubility and half-life of $12 \mathrm{hrs}$, bioavailability is only $30 \%$, due to its low permeability. ${ }^{7,8}$ In the present study floating polymeric nanoparticles of linagliptin were aimed as a novel approach to increase the residence time of drug in stomach by controlling drug delivery over a prolonged period of time and to increase permeability by nanosized particles, there by bioavailability can be increased. Nanoparticles are prepared by (ion gelation and desolvation methods) with ethyl cellulose, chitosan and gelatin as polymers. These are further converted into floating drug delivery with sodium bicarbonate and prolonging drug delivery using hydrophobic polymers like ethyl cellulose.

\section{MATERIALS AND METHODS}

\section{Materials}

Linagliptin was procured from Dr. Reddy's laboratories Ltd. Chitosan, Gelatin, sodium tri poly phosphate (STPP), glutaraldehyde, sodium bicarbonate, acetone, were procured from SD fine chemicals limited. Ethyl cellulose and HPMC E15M were procured from Yarrow Chem. Products. 


\section{Preparation}

\section{Ion Gelation Method}

The polymeric nanoparticles were prepared by Ion Gelation method, chitosan was soaked in $10 \mathrm{ml}$ of $1 \% \mathrm{v} / \mathrm{v}$ glacial acetic acid. To this mixture at $700 \mathrm{rpm}, 3 \mathrm{ml}$ of sodium tri poly phosphate (STPP) was added drop wise and continued stirring for 30 minutes to form a nanosuspension containing nanoparticles. Nanoparticles were filtered through Whatman's filter paper, washed and dried. ${ }^{9} 100 \mathrm{mg}$ of drug (linagliptin) was added to chitosan solution before addition of STPP. Drug: polymer ratio ranged from 1:0.25 to 1:1.25, which were coded as GF1 (1:0.25); GF2 (1:0.5); GF3 (1:0.75); GF4 (1:1) and GF5 (1:1.25) respectively.

\section{Desolvation method}

The polymeric nanoparticles were prepared by Desolvation method using gelatin as polymer. To $10 \mathrm{ml}$ of gelatin solution acetone was added either continuously ( $1 \mathrm{ml} / \mathrm{min}$ ) or intermittently ( $1 \mathrm{ml}$ for every $5 \mathrm{~min}$ ) at 700rpm to form turbid solution. To this nanosuspension few $\mathrm{ml}$ of $25 \% \mathrm{v} / \mathrm{v}$ glutaraldehyde was added with continuous stirring for $12 \mathrm{hrs}$. Then the solvent was removed in rotary flash vacuum evaporator and nanoparticles obtained were kept for air drying. ${ }^{10,11}$ Linagliptin was added to gelatin solution. Linagliptin: gelatin ratio ranged from 1:0.25 to 1:2, which were coded as CF1 (1:0.25); CF2 (1:0.5); CF3 (1:0.75); CF4 (1:1); CF5(1:1.25); CF6(1:1.5); CF7(1:1.75); and CF8 (1:2) respectively for continuous addition of acetone and as IF1 (1:0.25); IF2 (1:0.5); IF3 (1:0.75); IF4 (1:1); IF5(1:1.25); ICF6(1:1.5); IF7(1:1.75); and IF8 (1:2) respectively for intermittent addition of acetone.

\section{Preparation of floating polymeric nanoparticles of linagliptin}

optimized polymeric nanoparticles (GF2 formulation by ion gelation method) were converted to floating by addition of $10 \%$ of sodium bicarbonate and different concentrations of ethyl cellulose and HPMC E $15 \mathrm{M}$ as polymers which were filled into size ' 5 ' capsules. Quantities taken are given in Table 1.

Table 1: Preparation of floating polymeric nanoparticles of linagliptin.

\begin{tabular}{cccccc}
\hline Ingredients & GF2(1:0.5) & GF2(1:1) & GF2(1:1.5) & GF2(1:2) & GF2(1:2)EH \\
\hline $\begin{array}{c}\text { Polymeric } \\
\text { nanoparticles } \\
\text { (mg) }\end{array}$ & $\begin{array}{c}\text { Equivalent } \\
\text { amount } \\
\text { of drug } \\
\text { dose(7.5) }\end{array}$ & $\begin{array}{c}\text { Equivalent } \\
\text { amount } \\
\text { of drug } \\
\text { dose(7.5) }\end{array}$ & $\begin{array}{c}\text { Equivalent } \\
\text { amount } \\
\text { of drug } \\
\text { dose(7.5) }\end{array}$ & $\begin{array}{c}\text { Equivalent } \\
\text { amount } \\
\text { of drug } \\
\text { dose(7.5) }\end{array}$ & $\begin{array}{c}\text { Equivalent } \\
\text { amount } \\
\text { of drug } \\
\text { dose(7.5) }\end{array}$ \\
$\begin{array}{c}\text { Ethyl } \\
\text { cellulose (mg) } \\
\text { HPMC E }\end{array}$ & 3.75 & 7.5 & 11.25 & 15 & 7.5 \\
$\begin{array}{c}15 \mathrm{M}(\mathrm{mg}) \\
\text { Total }\end{array}$ & - & - & - & - & 7.5 \\
weight(mg) & 12.37 & 16.5 & 20.62 & 24.75 & 24.75 \\
\hline
\end{tabular}

Note: Where, GF2 (1:0.5) = formulation with $1 \%$ GF2 and $0.5 \%$ ethyl cellulose as polymer;

GF2 (1:1) = formulation with $1 \%$ GF2 and $1 \%$ ethyl cellulose as polymer;

GF2 (1:1.5) = formulation with $1 \%$ GF2 and $1.5 \%$ ethyl cellulose as polymer;

GF2 (1:2) = formulation with $1 \%$ GF2 and $2 \%$ ethyl cellulose as polymer;

GF2 (1:2) EH= formulation with $1 \%$ GF2 and 2\% ethyl cellulose and HPMC E $15 \mathrm{M}$ (in1:1) as polymer;

$1 \%$ GF2 = equivalent amount of drug dose;

\section{Drug-excipient compatibility was studied by FTIR and DSC}

The spectrum analysis of pure drug and physical mixture of drug with different polymers (chitosan and gelatin) which are used for preparation of nanoparticles was studied by FTIR and DSC. FTIR spectra were recorded by preparing potassium bromide $(\mathrm{KBr})$ disks using a shimadzu (Koyto, Japan) facility (model-8400S). Potassium bromide (KBr) disks were prepared by mixing few $\mathrm{mg}$ of sample with potassium bromide by compacting in a hydraulic press under vacuum at 6-8 tons pressure. The resultant disc was mounted in a suitable holder in IR spectrophotometer and the IR spectrum was recorded from $4000 \mathrm{~cm}$ to $500 \mathrm{~cm}$ in a scan time of $12 \mathrm{~min}$. The resultant spectrum was compared for any spectra changes. They were observed for the presence of characteristic peaks for the respective function functional group. ${ }^{12}$

DSC (differential scanning calorimetry) analysis was performed by using Q-1000 TA Instruments, USA. The instrument was calibrated with indium standard. Accurately 3-5 mg samples were weighed and placed in a closed, hermetic sample pans with pin hole. Thermo grams were obtained by heating the sample at a constant rate $10^{\circ} \mathrm{C} / \mathrm{min}$. A dry purge of nitrogen gas $(50 \mathrm{ml} / \mathrm{min})$ was used for all runs. Samples were heated from $0^{\circ} \mathrm{C}$ to $350^{\circ} \mathrm{C}$. The melting point, heat of fusion, disappearance of the crystalline sharp peak of the drug and appearance of any new peak and peak shape were noted. ${ }^{12}$

\section{Evaluation of polymeric nanoparticles and floating polymeric nanoparticles}

\section{Percentage yield}

The prepared drug loaded polymeric nanoparticles were collected and weighed. The weight obtained is noted as practical yield. The percentage yield was calculated by following formula. ${ }^{13}$

$$
\% \text { yield }=\frac{\text { Practical yield }}{\text { Theoretical yield }} \times 100
$$

\section{Determination of Drug content}

Polymeric nanoparticles equivalent to $5 \mathrm{mg}$ of drug were dissolved in methanol and kept for stirring at $600 \mathrm{rpm}$ for 3 hours respectively. The amount of the drug present in the supernatant was determined spectrophotometrically. ${ }^{14}$

\section{Drug Entrapment Efficiency}

Polymeric nanoparticles equivalent to $5 \mathrm{mg}$ of drug were taken in $2 \mathrm{ml}$ of distilled water and separated from the aqueous medium by ultracentrifugation at $10,000 \mathrm{rpm}$ for $30 \mathrm{~min}$ at $5^{\circ} \mathrm{C}$. Then the resulting supernatant solution was decanted and dispersed into 0.1 NHCL. The amount of drug entrapped in the nanoparticles was determined as the difference between the total amount of drug used to prepare the nanoparticles and the amount of drug present in the aqueous medium. ${ }^{15}$ The determination of entrapment efficiency was repeated three times per sample. The percentage drug entrapment was calculated using the following equation:

$$
\% \text { Drug entrapment }=\frac{\text { Amount of entrapped drug recovered }}{\text { Total amount of drug }} \times 100
$$

The polymeric nanoparticles of linagliptin and floating polymeric nanoparticles were filled in size ' 5 ' capsules with drug equivalent amount and evaluated for following parameters, 


\section{Weight variation}

Twenty capsules were selected at random and were weighed collectively and individually. From the collective weight, average weight was calculated. The $\%$ weight variation is calculated.

\section{Content Uniformity}

Twenty capsules were randomly selected from each batch of the prepared polymeric nanoparticles of linagliptin filled in capsules and their contents were removed and powdered. From this sample, powder (equivalent to drug dose) is accurately transferred in to $10 \mathrm{ml}$ volumetric flask. The volume is made up with methanol and sonicated for $30 \mathrm{~min}$. Then, $1 \mathrm{ml}$ of the above solution is transferred in to $10 \mathrm{ml}$ volumetric flask and the volume is made up to the mark with $0.1 \mathrm{~N} \mathrm{HCl}$. The solution is filtered through whatman filter paper and suitably diluted and the drug content was estimated spectrophotometrically by measuring absorbance at $238 \mathrm{~nm}$.

\section{Zeta potential and particle size}

The particle size and zeta potential were measured by photon correlation spectroscopy (Delsa Nano, Beckman Coulter Inc. UK). ${ }^{16}$

\section{SEM}

Scanning electron microscopy (SEM) was used to characterize the surface morphology of the prepared nanoparticles. Nanoparticle suspension was mounted on a clear-glass stub, air-dried, gold coated with Polaron E5100 sputter coater (Polaron, United Kingdom) and visualized under scanning electron microscope (Jeol 5400, Japan). ${ }^{17,18}$

\section{Floating time}

In this test the capsule filled with drug equivalent amount of linagliptin loaded floating polymeric nanoparticles is introduced into a $100 \mathrm{ml}$ beaker containing $0.1 \mathrm{~N} \mathrm{HCl}$ and the total duration of time for which dosage form remain floating is called floating time. ${ }^{19}$

\section{In-vitro drug diffusion studies}

Diffusion studies were performed using Franz diffusion cell with dialysis membrane. The cell was locally fabricated and therefore the volume of receptor compartment was $25 \mathrm{ml}$. The dialysis membrane used for diffusion studies was placed between donor and receptor compartment. Drug equivalent polymeric nanoparticles was placed on membrane and clamped together. The receptor compartment was filled with $0.1 \mathrm{~N} \mathrm{HCl}$ and maintained by continuous stirring at $400 \mathrm{rpm}$ with a magnetic bead and maintained at $37^{\circ} \mathrm{C}$. At predetermined time intervals, $1 \mathrm{ml}$ samples were withdrawn and replaced with an equal volume of buffer. The samples were analysed after appropriate dilution at $\lambda \max$ of $238 \mathrm{~nm}$ using spectrophotometer. From this cumulative amount permeated was calculated and plotted against function of time to study the pattern of drug permeated. ${ }^{13}$

\section{In-vitro drug Dissolution studies}

Dissolution studies were performed through dissolution apparatus using USP type-I (basket type) apparatus. The release of Linagliptin from the polymeric nanoparticles was studied using $0.1 \mathrm{~N} \mathrm{HCl}$ in a dissolution apparatus with a rotating basket stirrer at a stirring speed of $50 \mathrm{rpm}$ and a temperature of $37 \pm 1^{\circ} \mathrm{C}$. Drug equivalent amount of nanoparticles filled in size ' 5 ' capsules were used in each test and these were placed within each basket. Samples were withdrawn at different time intervals and replaced with $5 \mathrm{ml}$ of fresh dissolution medium. The withdrawn samples were assayed at $238 \mathrm{~nm}$ for linagliptin content using a UV visible spectrophotometer. ${ }^{16}$

\section{Ex-vivo permeability studies}

Ex-vivo permeability studies were carried out for optimized formulations (i.e. GF2 (1:2), GF2 formulations). Fresh intestinal tissue was removed from gastro intestinal tract (GIT) of goat obtained from local slaughter house. It was stored in saline water at frozen condition. The intestinal tissues were filled with formulations, tied to paddle by making them as pouch and the dissolution studies were carried out same as above procedure using $0.1 \mathrm{~N} \mathrm{HCl}$ as medium. From this, \% drug permeated was calculated and was plotted against the function of time to study the pattern of the drug release. ${ }^{19}$

\section{In-vitro drug release kinetics}

To study the mechanism and release kinetics, in-vitro release data were fitted with Zero order, First order, Higuchi release and Korsemeyer-Peppas mathematical models. ${ }^{12}$

\section{Stability study}

Optimized formulation i.e. GF2 (1:2) formulation was tested for stability in ambered colored bottle containers. It was stored at accelerated stability conditions $\left(40^{\circ} \mathrm{C} \pm 2^{\circ} \mathrm{C} / 75 \% \pm 5 \% \mathrm{RH}\right)$ as per $\mathrm{ICH}$ guidelines over a period of 1 month in a humidity chamber and in between the capsules were evaluated for drug content and in-vitro drug release every week. ${ }^{12}$

\section{RESULTS}

Polymeric nanoparticles were prepared using gelatin and chitosan polymers. And floating polymeric nanoparticles were prepared using ethyl cellulose and HPMC E15M. Drug-excipient compatibility with all polymers was studied by FTIR and DSC. The spectra of pure drug and optimized formulation GF2 (1:2) is given in Figure 1, which shows characteristic peaks at $1400,1540,1780 \mathrm{~cm}^{-1}$ representing C-N(stretching),

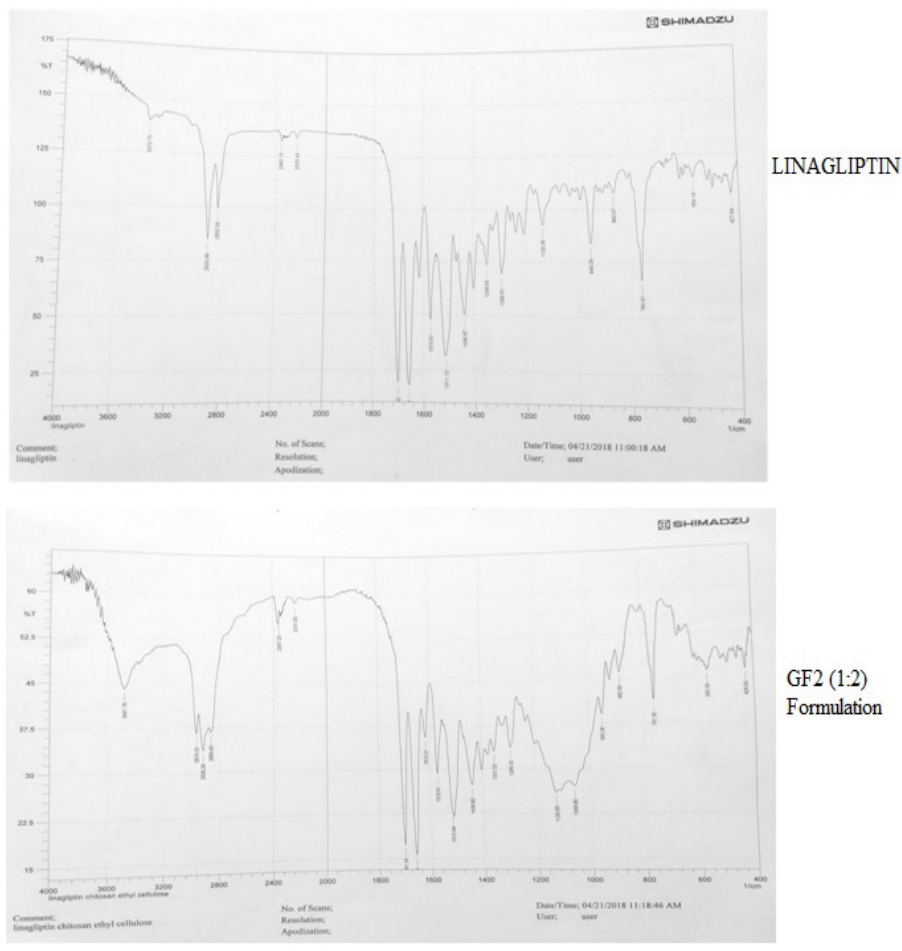

Figure 1: FTIR spectra of linagliptin and optimized floating polymeric nanoparticles formulation. 

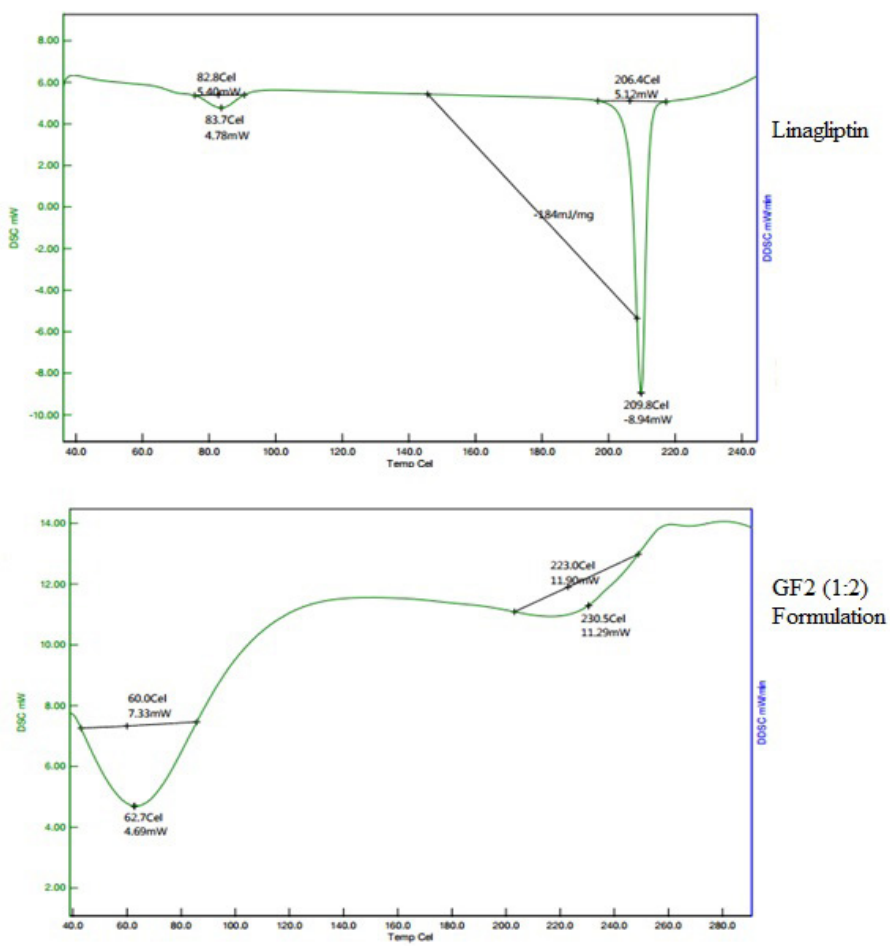

Figure 2: DSC scan of linagliptin and optimized floating polymeric nanoparticles formulation.

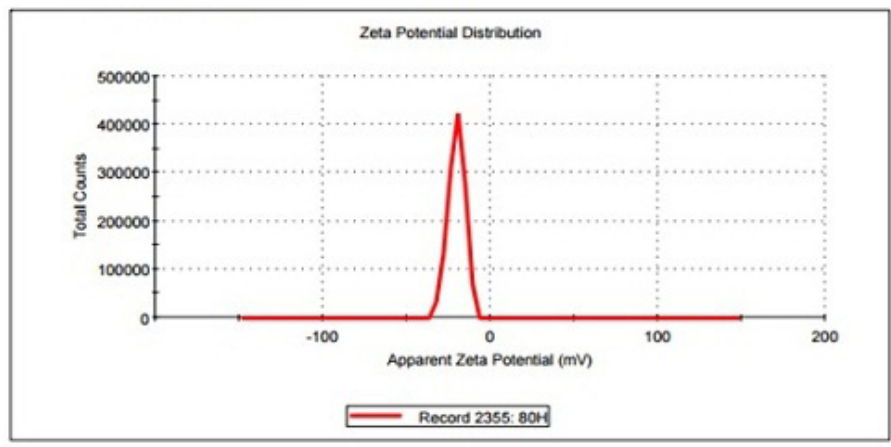

Figure 3: Zeta potential of GF2 formulation.

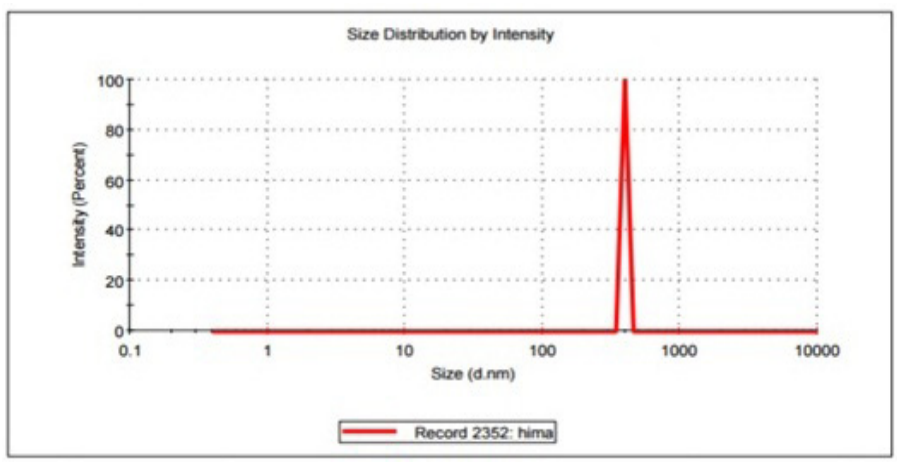

Figure 4: Particle size of GF2 formulation.
Table 2: Evaluation parameters of polymeric nanoparticles.

\begin{tabular}{|c|c|c|c|c|c|}
\hline 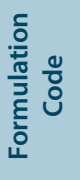 & 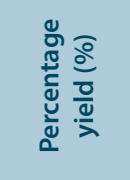 & 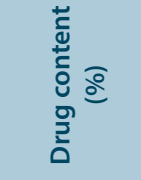 & 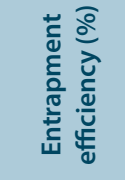 & 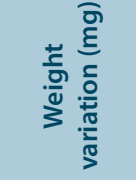 & 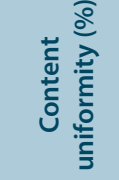 \\
\hline GF1 & $99.2 \pm 0.23$ & $93.8 \pm 0.12$ & $80.6 \pm 1.23$ & $88.3 \pm 1.32$ & $91.4 \pm 0.09$ \\
\hline GF2 & $100 \pm 0.46$ & $98.09 \pm 0.12$ & $88.6 \pm 1.09$ & $89.5 \pm 2.08$ & $98.9 \pm 0.24$ \\
\hline GF3 & $100 \pm 0.49$ & $75.7 \pm 0.08$ & $74.0 \pm 0.75$ & $90.7 \pm 2.08$ & $96.8 \pm 0.24$ \\
\hline GF4 & $100 \pm 0.27$ & $74.1 \pm 0.46$ & $73.0 \pm 0.81$ & $92.5 \pm 2.52$ & $97.3 \pm 0.17$ \\
\hline GF5 & $100 \pm 0.66$ & $72.3 \pm 0.78$ & $71.6 \pm 0.43$ & $93.3 \pm 3.05$ & $93.1 \pm 0.50$ \\
\hline CF1 & $100 \pm 0.17$ & $87.6 \pm 0.24$ & $69.3 \pm 0.26$ & $88.2 \pm 2.49$ & $97.4 \pm 0.33$ \\
\hline CF2 & $90.6 \pm 0.50$ & $71.9 \pm 0.33$ & $68.8 \pm 0.26$ & $88.9 \pm 4.12$ & $95.2 \pm 0.46$ \\
\hline CF3 & $84.0 \pm 0.34$ & $82.8 \pm 0.33$ & $52.5 \pm 0.45$ & $89.2 \pm 3.27$ & $92.4 \pm 0.73$ \\
\hline CF4 & $100 \pm 1.09$ & $74.2 \pm 0.49$ & $68.6 \pm 1.24$ & $92.0 \pm 2.49$ & $91.1 \pm 0.66$ \\
\hline CF5 & $88.0 \pm 0.81$ & $90.9 \pm 0.19$ & $58.9 \pm 0.31$ & $91.8 \pm 2.53$ & $93.1 \pm 0.12$ \\
\hline CF6 & $77.6 \pm 0.99$ & $89.5 \pm 0.19$ & $74.5 \pm 1.09$ & $91.7 \pm 3.21$ & $92.5 \pm 0.11$ \\
\hline CF7 & $80.7 \pm 1.23$ & $76.1 \pm 0.50$ & $74.0 \pm 1.09$ & $93.2 \pm 2.65$ & $98.8 \pm 0.32$ \\
\hline CF8 & $73.3 \pm 0.49$ & $77.6 \pm 0.50$ & $76.5 \pm 0.81$ & $93.1 \pm 4.37$ & $90.8 \pm 0.49$ \\
\hline IF1 & $98.4 \pm 0.66$ & $98.0 \pm 0.42$ & $63.4 \pm 0.78$ & $88.1 \pm 3.00$ & $95.4 \pm 0.49$ \\
\hline IF2 & $93.3 \pm 0.81$ & $80.4 \pm 0.08$ & $69.2 \pm 0.42$ & $89.0 \pm 2.09$ & $97.1 \pm 0.72$ \\
\hline IF3 & $61.1 \pm 0.73$ & $83.8 \pm 0.12$ & $61.6 \pm 0.94$ & $87.3 \pm 2.49$ & $93.5 \pm 0.19$ \\
\hline IF4 & $74.5 \pm 0.73$ & $81.4 \pm 0.78$ & $66.6 \pm 0.94$ & $89.4 \pm 2.37$ & $96.3 \pm 0.36$ \\
\hline IF5 & $93.7 \pm 1.00$ & $99.5 \pm 0.64$ & $58.0 \pm 0.27$ & $92.0 \pm 2.37$ & $95.4 \pm 0.24$ \\
\hline IF6 & $96.4 \pm 0.85$ & $70.4 \pm 0.24$ & $59.7 \pm 0.44$ & $94.0 \pm 2.49$ & $98.1 \pm 0.59$ \\
\hline IF7 & $97.4 \pm 0.97$ & $97.1 \pm 0.67$ & $61.8 \pm 1.02$ & $95.6 \pm 2.19$ & $90.9 \pm 0.59$ \\
\hline IF8 & $82.3 \pm 0.50$ & $70.9 \pm 0.78$ & $67.3 \pm 0.48$ & $94.3 \pm 2.07$ & $92.2 \pm 0.37$ \\
\hline
\end{tabular}

Values are expressed as mean $\pm \mathrm{SD}, \mathrm{n}=3$.

$\mathrm{N}-\mathrm{H}$ (Bending), $\mathrm{C}=\mathrm{O}$ (Stretching) respectively. DSC scan of pure drug and optimized formulation GF2 is given in Figure 2. The pure linagliptin showed melting endothermic peak at $206^{\circ} \mathrm{C}$, physical mixture showed endothermic peak at $223^{\circ} \mathrm{C}$.

Percentage yield, drug content, entrapment efficiency, weight variation and content uniformity results of polymeric nanoparticles are given in Table 2. Floating polymeric nanoparticles filled into capsules showed weight variation in range of $94.4 \pm 2.65 \mathrm{mg}$ to $107.1 \pm 2.59 \mathrm{mg}$ and content uniformity from $90.6 \pm 0.59 \%$ to $98.4 \pm 0.29 \%$.

Zeta potential, particle size and SEM of optimized formulation GF2 is given in Figure 3, Figure 4 and Figure 5 respectively.

Floating time results of formulations is given in Table 3.

In-vitro drug diffusion studies of polymeric nanoparticles prepared by ion-gelation method showed cumulative amount permeation from $733.7 \pm 3.00 \mu \mathrm{g} / \mathrm{cm}^{2}$ to $997.0 \pm 2.15 \mu \mathrm{g} / \mathrm{cm}^{2}$ in which $\mathrm{GF} 2$ formulation 
showed highest cumulative amount permeated of $997.0 \pm 2.15 \mu \mathrm{g} / \mathrm{cm}^{2}$ at $240 \mathrm{~min}$ and GF5 showed lowest cumulative amount permeated of $733.7 \pm 3.00 \mu \mathrm{g} / \mathrm{cm}^{2}$ at $150 \mathrm{~min}$. In desolvation method by continuous addition, range of permeated amount was from $720.1 \pm 3.25 \mu \mathrm{g} / \mathrm{cm}^{2}$ to $924.1 \pm 0.90 \mu \mathrm{g} / \mathrm{cm}^{2}$. CF5 formulation showed highest cumulative amount permeated of $924.1 \pm 0.90 \mu \mathrm{g} / \mathrm{cm}^{2}$ at $240 \mathrm{~min}$ and CF2 formulation showed lowest cumulative amount permeated of $720.1 \pm 3.25 \mu \mathrm{g} / \mathrm{cm}^{2}$ at $150 \mathrm{~min}$. In intermittent addition, $616.1 \pm 0.70 \mu \mathrm{g} / \mathrm{cm}^{2}$ to $993.1 \pm 3.24 \mu \mathrm{g} / \mathrm{cm}^{2}$ range of drug permeation was seen with formulations. Within these, IF1 showed highest cumulative amount permeated of $993.1 \pm 3.24 \mu \mathrm{g} / \mathrm{cm}^{2}$ at $240 \mathrm{~min}$ and the IF6 formulation showed lowest cumulative amount permeated of $616.1 \pm 0.70 \mu \mathrm{g} / \mathrm{cm}^{2}$ at $120 \mathrm{~min}$.

Dissolution studies of polymeric nanoparticles prepared by ion gelation method showed drug release range from $91.8 \pm 0.50 \%$ to $97.4 \pm 0.12 \%$ in $210 \mathrm{~min}$, continuous addition in desolvation method showed $91.0 \pm 0.46 \%$ to $99.8 \pm 0.08 \%$ in $150 \mathrm{~min}$ and in intermittent addition range was from $91.5 \pm 0.31 \%$ in $210 \mathrm{~min}$ to $99.2 \pm 0.19$ in $60 \mathrm{~min}$. GF2 formulation showed the drug release of $91.8 \pm 0.50 \%$ in $210 \mathrm{~min}$, CF5 of $92.8 \pm 0.33 \%$ at $210 \mathrm{~min}$ and IF 1 of $91.5 \pm 0.31 \%$ at $210 \mathrm{~min}$ indicating the sustained / delayed release of drug from the formulation.

Percentage drug release of floating polymeric nanoparticles is given in Figure 6.

Ex-vivo permeability studies of optimized formulations GF2 nanoparticles, GF2 nanoparticles in capsule, GF2 (1:2) floating polymeric nanoparticles were performed in comparison with pure drug using fresh intestinal tissue of goat. The percentage drug permeated is given in Figure 7.

In-vitro drug release kinetics of optimized formulations GF2, CF5, IF1 and GF2 (1:2) are given in Table 4.

A stability study of optimized floating polymeric nanoparticles was performed for one month according to ICH guidelines. Physical appearance, drug content and percentage drug release parameters were evaluated every week.

\section{DISCUSSION}

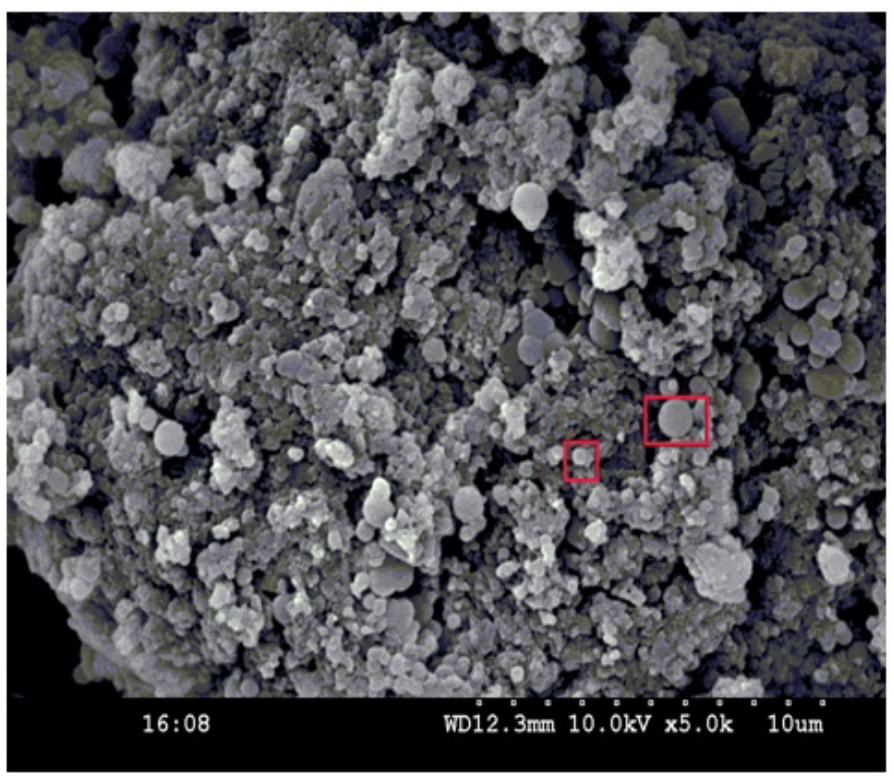

Figure 5: SEM photograph of GF2 formulation.
Polymeric nanoparticles were prepared by ion gelation method and desolvation method. The wave numbers of the principal peaks of linagliptin appeared as characteristic peaks in the IR graphs of physical mixture of drug with excipient. Thermal behaviour of pure linagliptin and their physical mixture indicates no interaction between drug and excipient. Thus the excipients were found to be compatible. ${ }^{12}$

The prepared nanoparticles were evaluated for various physico chemical properties and IF3 formulation showed the lowest percentage yield of $61.1 \pm 0.73 \%$ while rest of the formulations are within the acceptable limits i.e., within the range of $70-100 \%$. Drug content of all the formulations are within the acceptable limits i.e., within the range of $70-100 \%$ indicating that there is no loss of drug. Formulation GF2 showed the highest entrapment efficiency of $88.6 \pm 1.09 \%$, formulation IF5 showed the lowest entrapment efficiency of $58.0 \pm 0.27 \%$ while rest of the formulations showed entrapment efficiency in the range of $60 \%$ to $80 \%$. All the capsules passed the weight variation test as the average percent weight variation was within $7.5 \%$ limits as prescribed in the pharmacopoeia. GF2 (1:2) formulation showed the highest content uniformity of

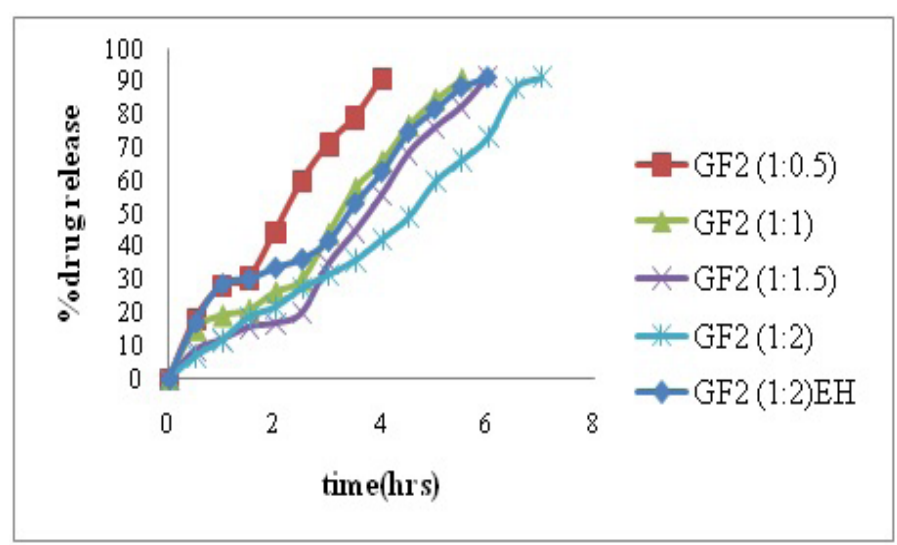

Figure 6: Percentage drug release of floating polymeric nanoparticles of linagliptin.

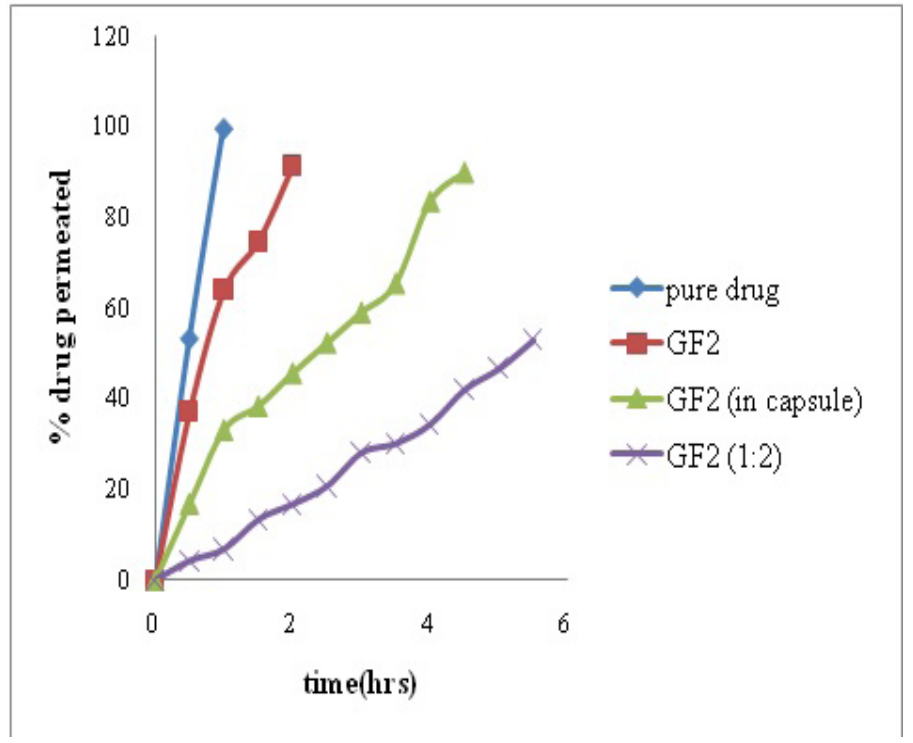

Figure 7: Percentage drug permeated in ex-vivo studies in comparison with pure drug. 
Table 3: Floating time of floating polymeric nanoparticles formulations of linagliptin.

\begin{tabular}{cc}
\hline Formulation code & Floating time \\
\hline GF2(1:0.5) & $6 \mathrm{hrs} 47 \mathrm{~min}$ \\
GF2(1:1) & $7 \mathrm{hrs}$ \\
GF2(1:1.5) & $7 \mathrm{hrs} 20 \mathrm{~min}$ \\
GF2(1:2) & $8 \mathrm{hrs}$ \\
GF2(1:2)EH & $7 \mathrm{hrs} 56 \mathrm{~min}$ \\
\hline
\end{tabular}

$98.4 \pm 0.29 \%$ and the other formulation showed the content uniformity ranging from $90.6 \%$ to $97.1 \%$.

Zeta potential is useful in knowing the surface charge of the particle which can determine its stability. ${ }^{20}$ Nanoparticles with a zeta potential above $( \pm) 30 \mathrm{mV}$ have been shown to be stable in suspension, as the surface charge prevents aggregation of the particles. The formulation GF2 has shown a Zeta potential of $-20.3 \mathrm{mV}$. Particle size and size distribution are the most important characteristics of nanoparticle systems. ${ }^{21}$ The particle size distribution of particles is expressed in PDI. GF2 has shown a particle size of $396 \mathrm{~nm}$ and PDI of 1.0 from which it can inferred that nano range has been formulated and the particle size possess large

Table 4: Drug release kinetics of optimized formulations.

\begin{tabular}{|c|c|c|c|c|c|c|}
\hline Formulation code & \multicolumn{4}{|c|}{$R^{2}$} & $\begin{array}{c}\text { Korsmeyer-Peppas } \\
\boldsymbol{n}\end{array}$ & Drug transport mechanism \\
\hline GF2 & 0.988 & 0.856 & 0.944 & 0.957 & 0.526 & Anomalous transport. \\
\hline CF5 & 0.957 & 0.895 & 0.985 & 0.991 & 0.508 & Anomalous transport. \\
\hline IF1 & 0.989 & 0.947 & 0.988 & 0.986 & 0.480 & Fickian diffusion \\
\hline
\end{tabular}

interfacial surface area for drug absorption. The linagliptin nanoparticles were evaluated for their surface morphology using SEM. The nanoparticles were found to be discrete, spherical with smooth surface..$^{22,23}$

From in vitro drug release studies, even though GF2 formulation by ion gelation method, CF5 by desolvation (continuous addition) method and IF1 by desolvation (intermittent addition) method can be optimized based on their percent drug release of $91.8 \pm 0.50 \%, 92.8 \pm 0.33 \%$ and $91.5 \pm 31 \%$ in $210 \mathrm{~min}$ respectively. GF2 was considered as the optimized formulation based on its high entrapment efficiency and cumulative amount permeated of $997.0 \pm 2.15 \mu \mathrm{g} / \mathrm{cm}^{2}$ for $240 \mathrm{~min}$ ( $4 \mathrm{hrs}$ ). Thus GF2 formulation obtained by ion gelation method was further converted into floating delivery system to increase the drug residence time by making them to float, which enhance the permeability thereby the bioavailability can be increased. GF2 (1:2) formulation showed highest floating time of $8 \mathrm{hrs}$. Since the lag time depends upon amount of sodium bicarbonate involved in carbon dioxide formation and polymer used, tough the same concentration of sodium bicarbonate (10\%) was used in all formulations, floating time is varying based on the concentration of polymer used. However all formulations exhibited satisfactory floatation ability and remained floating for $6-8 \mathrm{hrs}$ in the dissolution medium (0.1N HCL). GF2 (1:2) showed the delayed drug release of $91.5 \pm 0.50 \%$ at $7 \mathrm{hrs}$, indicating the increase in the residence time of the drug in the stomach. The pure drug showed the permeation across the goat intestine of $99.8 \pm 0.19 \%$ at $1 \mathrm{hr}$, where as GF2 (1:2) formulation showed permeation of $53.1 \pm 0.50 \%$ in $5.5 \mathrm{hrs}$ by retaining the drug. Hence the increase in permeation of the drug has been achieved. It is observed from release kinetics GF2 (1:2) formulation followed zero order release kinetics with super case -II transport mechanism. The formulation was also stable for one month at accelerated stability conditions according to ICH guidelines. ${ }^{12}$

\section{CONCLUSION}

Floating polymeric nanoparticles of linagliptin prepared by ion gelation method using chitosan and ethyl cellulose were able to increase the residence time of drug in stomach by floating and retarding drug release, permeability of drug was enhanced by nano size of particles. Hence the objective of enhancing bioavailability is achieved.

\section{ACKNOWLEDGEMENT}

The authors would like to acknowledge G.Pulla Reddy College of Pharmacy for providing the facilites for research work.

\section{REFERENCES}

1. Mohanlal VJ, Chen Y. Nanoparticles: Review. TJPR. 2006;5(1):561-73

2. Aarti PN, Mukesh PR, Shilpa PC. Nanoparticles: An overview. IJRD. $2014 ; 3(5): 1121-7$.

3. Kuldeep M, Singh SK, Mishra DN, Birender S. Nanoparticles: An Advance Technique for Drug Delivery. RJPBCS. 2012;3(3):1186-208.

4. Abhishek G, Sharad V, Pramod KS, Nitin K. Formulation, Characterization and Application on Nanoparticle: A Review. Pelagia Research Library. 2011;2(2):17-26.

5. Adriana PHB, María TAM, Manuel ICH, Leandro JMO. Preparation of chatoyant nanoparticles modified with sodium alginate with potential for controlled drug release. Technical-scientifical Biannual Publication. 2016;12(3):75-83.

6. Archana. Formulation and Evaluation of Naproxen Sodium Loaded Bovin Serum Albumin Nanoparticles by Desolvation Technique. AJPTI. 2015;03(14):23-33.

7. Navaneetha K, Navya A, Venkateshwara B, Reddy T, Saritha NJ. Formulation and in-vitro evaluation of nanoparticles of linagliptin. WJPR. 2017:6(7):1319-28.

8. Prasanthi D, Yanmanagandla D, Sripada RD. Formulation and evaluation of linagliptin mucoadhesive microspheres. Int Res J Pharm. 2018;9(5):11-7.

9. Kalpana N, Shailendra KS, Dina NM. Chitosan Nanoparticles: A Promising System in Novel Drug Delivery. Chemical and Pharmaceutical Bulletin. 2010;58(11):1423-30.

10. Krishna SS. Preparation of sodium alginate nanoparticles by desolvation technique using is propyl alcohol as desolvating agent. IJAP. 2015;4 ( 5 ):2320-4923.

11. Krishna S, Chandavath V. Preparation and characterization of mefenamic acid loaded bovine serum albumin nanoparticles by desolvation technique using acetone as desolvating agent. Scholars Research Library. 2014;6(6):207-26.

12. Amoolya C, Prasanthi D. Solubility Enhancement of Aripiprazole by Solid-Self Emulsifying Drug Delivery Systems. Int J Pharm Sci Drug Res. 2018;10(4):233-45.

13. Krishna AK, Amareshwar P, Chakravarty P. Different techniques used for the preparation of nanoparticles using natural polymers and their application. Int $\mathrm{J}$ Pharm Pharm Sci. 2011;3(2):45-50.

14. Aenugu SR, Abba RKS. Preparation and Characterization of aspirin loaded ethyl cellulose nanoparticles by solvent evaporation technique. WJPPS. 2014;3(6):81-93.

15. Amulyaratna B, Sunit KS. Preparation and evaluation of glibenclamide-loaded biodegradable nanoparticles. TJPR. 2012;11(3):345-50. 
16. Anto S, Azhagesh R, Bharathi S. Preparation, characterization and evaluation of nanoparticles containing hypolipidemic drug and antihypertensive drug. IJBA. 2011;2(3):949-53.

17. Alshamsan A. Nanoprecipitation is more efficient than emulsion solvent evaporation method to encapsulate cucurbitacin I in PLGA nanoparticles. Saudi Pharm J. 2014;22(3):219-22.

18. Patel R, Gajra B, Parikh RH, Gayatri P. Ganciclovir Loaded Chitosan Nanoparticles: Preparation and Characterization. Journal of Nanomedicine and Nanotechnology. 2016;7(6):1-8.

19. Pavan KP, Sree P. Formulation and in vitro evaluation of floating microspheres of dextromethorphan hydrobromide. Materials Science. 2014;6(4):1-8.
20. Sree LV, Krishna S. Formulation of Mefenamic acid loaded polymeric nanoparticles by ionotropic gelation technique for the treatment of rheumatoid arthritis. International Journal of Advances in Pharmaceutics. 2016;5(6):151-9.

21. Nagarwal RC, Kant S, Singh PN, Maiti P, Pandit JK. Polymeric nanoparticulate system. J Control Release. 2009;136(1):2-13.

22. Nagavarma BVN, Hemant KS, Yadav AA, Vasudha LS, Shiva KHG. Different techniques for preparation of polymeric nanoparticles: A review. Asian J Pharm Clin Res. 2012; 5(3): 16-23.

23. Naha A, Kiran S, Rai I, Vora B, Reddy DA, Kartika P. Preparation and evaluation of polymeric nanoparticles of glibenclamide. JDDT. 2014;4(5):190-2.

Article History: Submission Date : 09-03-2020; Revised Date : 03-05-2020; Acceptance Date : 07-06-2020.

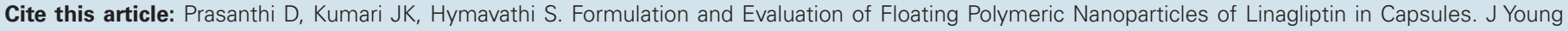
Pharm. 2020;12(2)Suppl:s32-s8. 